\title{
Methane and carbon dioxide emissions during electric power production
}

\author{
Denis Zastrelov*, Ekaterina Lukina, and Ekaterina Snetova \\ Federal Research Center for Coal and Coal Chemistry SB RAS, 650000, Kemerovo, Russia
}

\begin{abstract}
The amount of greenhouse gas emissions in the "Energy sector" on the territory of the Russian Federation is presented. The estimate of potential for greenhouse gas emissions reduction in the energy sector is considered. Recommendations for reducing greenhouse gas emissions in the "Energy sector" are provided.
\end{abstract}

\section{Introduction}

The increasing concentration of greenhouse gases (GHG) in the atmosphere is a global environmental threat to the environment and economic development worldwide. The world community is making efforts to reduce anthropogenic greenhouse gas emissions. At the heart of the developed, implemented and already existing methods of limiting GHG in the Earth's atmosphere lies the quantification, monitoring, reporting and verification of greenhouse gas emissions [1].

The most significant sector of the GHG inventory is the energy sector. This sector in the Russian Federation accounts for about $80 \%$ of the total GHG emissions [1].

The presence of greenhouse gases in the planet's atmosphere leads to the retention the part of the thermal radiation from the earth's surface in the lowest atmospheric stratum. The consequence of greenhouse gases concentration increase is a gradual heating of the planet's surface, further leading to climatic changes. Climate change, in its turn, can be characterized by negative consequences in resource consumption and production $[2,3]$. Therefore, the growing concentration of greenhouse gases is a global hazard for the environment and economic development.

\section{Analysis}

In order to implement the anthropogenic GHG gas emissions reduction from the level of emissions in 1990, the Paris Agreement was adopted within the framework of the UN Framework Convention on Climate Change. This agreement was signed in 2016 by almost 200 member countries, including Russia. To fulfill the obligations assumed in accordance with the signed agreement, the Decree of the President of the Russian Federation No. 666 of 04.11.2020 "On the reduction of greenhouse gas emissions" was issued, according to

\footnotetext{
*Corresponding author: zastrelov@uglemetan.ru
} 
which it is necessary to ensure greenhouse gas emissions reduction to $70 \%$ by 2030 relative to the 1990 year level [4].

The largest share of the total GHG emissions is attributed to the "Energy Sector". Typically, the energy sector accounts for over $90 \%$ of $\mathrm{CO}_{2}$ emissions and $75 \%$ of total greenhouse gas emissions in developed countries. Within the sector, stationary combustion usually accounts for about $70 \%$ of greenhouse gas emissions, while mobile combustion accounts for about a quarter of emissions [5]. Energy systems in most economies are largely determined by the combustion of fossil fuels. In doing so, carbon and hydrogen from fossil fuels are mainly converted to carbon dioxide $\left(\mathrm{CO}_{2}\right)$ and water $\left(\mathrm{H}_{2} \mathrm{O}\right)$, releasing the chemical energy of the fuel and converting it into heat. This heat is used either directly or to generate mechanical energy, most often to generate electricity or for transportation [5].

Share of the "Energy sector" in the Russian Federation in 1990-2015. dominated in total amount of greenhouse gas emissions. In the period under review, emissions from the energy sector averaged $81-83 \%$, emissions from industry amounted to $7-8 \%$, the share of the "Agriculture" sector - 5-8\%, "Waste" - 2-4\% [6].

On the territory of the Kemerovo Region, in accordance with the "Methodological Recommendations for Conducting a Voluntary Inventory of Greenhouse Gas Emissions in the Constituent Entities of the Russian Federation, Approved by Order of the Ministry of Natural Resources and Environment of the Russian Federation No. 15-r dated 04.16.2015, the estimate of greenhouse gas emissions for the periods 1990, 2014-2018 was carried out. Emissions in the "Energy sector" on the territory of Kemerovo Region for the regarded period constitute $65-70 \%$ of the total amount of regional emissions.

Greenhouse gas emissions in the "Energy sector" are represented by emissions of $\mathrm{CO}_{2}$, $\mathrm{CH}_{4}, \mathrm{~N}_{2} \mathrm{O}$, that are produced during fuel combustion to generate heat and electricity (stationary combustion), $\mathrm{CO} 2$ emissions - during motor fuel combustion by vehicles, $\mathrm{CO}_{2}$ and $\mathrm{CH} 4$ - during fugitive emissions.

Aggregate GHG emissions in the "Energy sector" of Kemerovo region for the periods 1990, 2014-2018 are presented in Table 1.

Table 1. Aggregate greenhouse gas emissions in the "Energy sector" of Kemerovo region.

\begin{tabular}{|c|c|c|c|c|c|c|}
\hline \multirow[t]{2}{*}{ Category } & \multicolumn{6}{|c|}{ GHG emissions (thousand $\mathrm{tCO}_{2} \mathrm{e}$ ) } \\
\hline & 1990 year & 2014 year & 2015 year & 2016 year & 2017 year & 2018 year \\
\hline $\begin{array}{c}\text { Fuel } \\
\text { stationary } \\
\text { combustion }\end{array}$ & 0 & 54002.10 & 62685.29 & 52983.53 & 50953.76 & 47820.12 \\
\hline $\begin{array}{l}\text { Transport } \\
\text { emissions }\end{array}$ & 0 & 4228.95 & 4527.35 & 4654.14 & 5180.99 & 5882.08 \\
\hline $\begin{array}{c}\text { Fugitive } \\
\text { emissions }\end{array}$ & 31023.69 & 37084.94 & 36747.19 & 38862.20 & 41977.0 & 44282.51 \\
\hline $\begin{array}{c}\text { Total } \\
\text { (thousand } \\
\mathrm{tCO}_{2} \mathrm{e} \text { ) }\end{array}$ & 31023.69 & 95315.99 & 103959.84 & 96499.87 & 98112.46 & 97984.72 \\
\hline
\end{tabular}

\section{Conclusion}

Based on Table 1 showings, we can conclude that the main share of emissions falls on the categories "Stationary fuel combustion" - 48-55\% and "Fugitive emissions" - 40-45\%.

Regarding the necessity of GHG emissions reduction and the presented results, it can be concluded that primarily it is advisable to undertake greenhouse gas emissions reduction measures in the "Energy sector". This sector has the greatest potential for GHG reduction 
since the "Energy sector" products are used in all other economy sectors, which will indirectly affect the reduction of greenhouse gas emissions in them.

The need to realize the emissions reduction potential should be considered not only on the basis of the Russian Federation President Decree No. 666 dated November 4, 2020 provisions but also in the light of the implementation of regulatory government documents, such as the Energy Strategy of Russia for the period up to 2035. This Strategy emphasizes the low level of energy efficiency in the country, sets directions for the development of energy efficiency and energy conservation. The reference point "sustainable energy development" has been formed, which is a consequence of the revision of the reference point "environmental safety of energy" of the Energy Strategy of Russia for the period up to 2030, and contains: the requirements of social responsibility, environmental safety and innovative development.

Actions aimed at reducing greenhouse gas emissions in the energy sector can be implemented in four areas:

- increasing the energy efficiency of industrial enterprises and housing and communal services as a result of measures to reduce the energy consumption level [2];

- modernization of heat energy transportation and distribution systems;

- introduction of technologies for thermal and electric power generation using alternative energy sources [3];

- improving fuel efficiency of vehicles and promoting the use of alternative fuels.

Improving the energy efficiency of industrial enterprises and housing and communal services implies the following measures:

1. The use of modern energy-efficient lighting (for a production room with an area of 10,000 sq. m. the replacement of fluorescent lighting with LED lighting within 5 years will allow to achieve savings of an average of $50 \%$. And this is taking into account the costs of buying and installing new lamps).

2. Replacement of office equipment with a high energy efficiency index (energy efficiency class $\mathrm{A}, \mathrm{A}+, \mathrm{A}++$ or $\mathrm{A}+++$ indicates that electricity consumption is $45 \%$ less than that of a conventional device. This marking is placed on energy-efficient equipment that can serve for about 15 years).

3. Installation of energy-saving windows and doors, mechanical ventilation systems with the function of recovery, so the use of secondary heat (energy-saving windows and doors contain glass (from the side of the room) coated with microparticles of semiconductor metal oxides, which reflects part of the heat rays falling on its surface. Due to the phenomena of interference and electrical conductivity, glass with such a coating reflects heat waves in the infrared range, which significantly reduces the heat loss of the room).

4. Thermal insulation of buildings, attics, floors of the first floors, voids in the walls; sealing of baseboards and other places of heat leaks with the use of modern thermal insulation materials (repair of buildings is carried out on the basis of an assessment of their technical audit, which is carried out by conducting systematic scheduled and unplanned inspections using modern means of technical diagnostics).

Modernization of heat energy transportation and distribution systems implies the following measures:

1. Improving the insulation of old heating systems with polyurethane insulation, which, according to experts, can reduce losses by 2-3 times.

2. Construction of combined-cycle gas plants (CCGTs) with cogeneration mode (joint generation of electricity and heat, fuel efficiency of such plants during the annual cycle is $10 \%$ higher) instead of CCGTs operating in condensation mode.

3. Introduction of automated heating systems with room temperature regulation depending on changes in ambient temperature. Replacement of central heating radiators in the premises with modern designs. The heat consumption is reduced by up to $30 \%$. 
It is advisable to choose alternative energy sources for each region separately in accordance with climatic conditions. The use of alternative energy sources can be effective in remote areas of the region.

The potential to reduce greenhouse gas emissions by increasing the fuel efficiency of vehicles is based on technical improvements of vehicles (reducing the overall weight of the vehicle, optimizing aerodynamic properties, improving the efficiency of internal combustion engines).

The largest contribution to the category "Fugitive emissions" in the Kemerovo region is made by the coal mine methane (CMM) emission produced in the process of underground coal production. In this regard, the reduction of the coal mining negative impact can be achieved by rationalization of reclamation processes of lands disturbed in the course of implementation the technological measures for coal extraction. Lands reclamation involves two main stages: technical and biological.

One of the directions of biological reclamation is the forest reclamation, the purpose of which is to create new forests on lands disturbed by industry. Thus, the effective use of passive and active forest reclamation measures to increase the area of forest plantations is a potential tool for increasing the amount of greenhouse gases absorption.

Coal mine methane has the greatest potential for GHG emissions reduction by its use in power plants. This requires the following:

- to increase the share of methane recovery by degasification system ensuring it standard concentration in methane air mixtrure;

- to foresee the placement of utilization facilities in close proximity to a potential consumer of heat and / or electricity; CMM.

- to increase the number of power plants that generate heat and / or electricity using

\section{References}

1. Guidelines for conducting a voluntary inventory of greenhouse gas emissions in the constituent entities of the Russian Federation, approved by the order of the Ministry of Natural Resources of Russia dated April 16, 2015 No. 15-r: http://www.consultant.ru

2. Types, sources of greenhouse gases and their impact on the Earth's climate: www.ozoneprogram.ru

3. Greenhouse effect: www.grandars.ru

4. Decree of the President of the Russian Federation as of 04.11.2020 No. 666 On the reduction of greenhouse gas emissions: www.kremlin.ru

5. IPCC Guidelines for National Greenhouse Gas Inventories: www.ipccnggip.iges.or.jp/public/2006gl/russian/index.html

6. The Seventh national communication of the Russian Federation, submitted in accordance with Articles 4 and 12 of the United Nations Framework Convention on Climate Change and Article 7 of the Kyoto Protocol: https://unfccc.int/files/national_reports/annex_i_natcom_/application/pdf/20394615_ru ssian_federation-nc7-1-7nc.pdf

7. O.V. Tailakov, D.N. Zastrelov, Science-intensive technologies for the development and use of mineral resources, 6, 358-363 (2020) 